\title{
A MATERIALIZAÇÃO DO DIREITO INTERNACIONAL PRIVADO BRASILEIRO: O CANCELAMENTO DA SÚMULA N² 207 DO TST.
}

\author{
MATERIALIZATION OF BRAZILIAN PRIVATE INTERNATIONAL LAW: THE \\ CANCELLING OF PRECEDENT N 207 OF THE SUPREME LABOR COURT
}

Marília Zanchet Rosa*

Sumário: 1. INTRODUÇÃO. 2. A INSUFICIÊNCIA DO MÉTODO CLÁSSICO NA PROTEÇÃO INTERNACIONAL DO EMPREGADO. 2.1. Normas clássicas. 2.2. Lex loci laboris. 3. A SOLUÇÃO POR MEIO DA MATERIALIZAÇÃO DO DIREITO INTERNACIONAL PRIVADO. 3.1. Normas de conexões abertas. 3.2. Favor empregado. 4. CONSIDERAÇÕES FINAIS. REFERÊNCIAS.

Resumo: As relações de trabalho, da mesma forma como relações privadas em geral, têm assumido caráter internacional. O crescente fenômeno acarreta, contudo, o incremento de vulnerabilidade do trabalhador. Em nível internacional, esse desafio aumenta, especialmente porque as normas conflituais clássicas foram construídas a partir da sociedade liberal moderna, que buscava basicamente a manutenção da igualdade formal entre os indivíduos, sem preocupações de cunho material. Embora as soluções tradicionais ainda estejam presentes no Direito Internacional Privado Brasileiro, um precedente recente do Tribunal Superior do Trabalho alterou essa realidade. Assim, este trabalho tenciona analisar os efeitos dessa decisão do TST na evolução do Direito Internacional Privado Brasileiro. Na primeira parte do trabalho será analisada a insuficiência do método clássico na proteção do empregado. A principal manifestação desse método está no elemento de conexão da lei do local da execução do contrato de trabalho, ou lex loci laboris. A segunda parte avalia a solução adotada pela jurisprudência do TST, ao cancelar a Súmula nº 207 e consagrar o elemento de conexão da lei

\footnotetext{
* Universidade Federal do Rio Grande do Sul.
} 
mais favorável ao empregado ou favor empregado como o principal para as relações de trabalho internacionais. Em conclusão, aborda-se o significado desse entendimento do TST para evolução do Direito Internacional Privado Brasileiro.

Palavras-chaves: Direito Internacional Privado; Direito Internacional do Trabalho; Conflitos de Lei no Espaço; Elementos de Conexão; Lei Mais Favorável ao Empregado.

Abstract: Labor relations, in the same way as private relations in general, have assumed an international character. The growing phenomenon entails, however, the increased vulnerability of the worker. On an international level, this challenge increases, especially because the Classic Conflict of Law Rules were built based on modern liberal society, whose basic aim was to maintain the formal equality between individuals, without any material concerns. Although traditional solutions are still present in Brazilian private international law, recent Supreme Labor Court precedent has changed this reality. Therefore, this paper intends to analyze the effects of this Supreme Labor Court decision in the Brazilian Private International Law. In the first part of this paper will be analyzed the insufficiency of the classical method in the employee protection. The main expression of this method lies in the connecting element of the law of the place of the labor contract, or lex loci laboris. The second part evaluates the solution adopted by the case law of the TST to cancel precedent $n^{\circ}$. 207 and consecrate the connecting element of the law most favorable to the employee, or employee favor, as the main connecting element for international labor relations. Concluding, the meaning of this understanding of the Supreme Labor Court decision for the evolution of Brazilian Private International Law is discussed.

Keywords: Private International Law; International Labor Law; Conflict of Law Rules; Connecting Elements; Law Most Favorable to the Employee.

\section{INTRODUÇÃO}

O fenômeno da globalização vem produzindo significativas alterações na sociedade nos dois últimos séculos ${ }^{1}$, gerando uma crescente internacionalização das relações privadas ${ }^{2}$.

\footnotetext{
${ }^{1}$ A respeito do impacto do fenômeno da globalização no Direito, FARIA, José Eduardo. O direito na economia globalizada. São Paulo: Malheiros, 1999.
} 
Consequentemente, houve um aumento do intercâmbio de trabalhadores entre os países ${ }^{3}$, ganhando relevo o Direito Internacional Privado do Trabalho ${ }^{4}$.

A particularidade dos conflitos de leis envolvendo trabalhadores está nas leis em conflito possuírem um papel social diferente, devendo atribuir assistência jurídica e proteção econômica ao trabalhador ${ }^{5}$. Assim, embora as normas de conflito, em si, não apresentem nenhuma particularidade, a solução delas decorrente requer cuidadosa atenção ${ }^{6}$.

Nesse sentido, vale um breve apanhado sobre o desenvolvimento do $\operatorname{DIPr}^{7}$ Brasileiro na atualidade $^{8}$. A disciplina foi codificada em 1917, com a edição da Introdução ao Código Civil. Essa lei, promulgada juntamente com o Código Civil de 1916, adotou, como regra de conexão relativa à capacidade, a lei da nacionalidade da pessoa envolvida, na linha dos países europeus, mas na contramão dos demais países latino-americanos que, em sua maioria, optaram pela regra do domicílio.

Em 1942, com a edição da Lei de Introdução ao Código Civil, Decreto-Lei n. ${ }^{\circ}$ 4.687/42, o DIPr Brasileiro sofre uma profunda alteração, objetivando se adequar às decorrências da imigração, à semelhança do que ocorria com os demais países latino-americanos, que adotavam a regra domiciliar. Observou-se, naquele momento, uma clara tentativa de modernização, não somente do DIPr Brasileiro, como também de todo o sistema de aplicação de normas jurídicas ${ }^{9}$.

Ao final do século XX, é editada a Constituição Federal de 1988. Nesse momento, o país demonstrou uma abertura para a questão internacional e de proteção dos direitos

\footnotetext{
2 FERNÁNDEZ ARROYO, Diego P. El derecho internacional privado en el inicio del siglo XXI. In: MARQUES, Cláudia Lima; ARAÚJO, Nádia de (Org.) O novo direito internacional: estudos em homenagem a Erik Jayme. Rio de Janeiro: Renovar, 2005, p. 89-110. Também, a respeito do tema: FRADERA, Véra Maria Jacob de. O direito dos contratos no século XXI: a construção de uma noção metanacional de contrato decorrente da globalização, da integração regional e sob influência da doutrina comparatista. In: DINIZ, Maria Helena; LISBOA, Roberto Senise. O direito civil no século XXI. São Paulo: Saraiva, 2003, p. 500-503.

${ }^{3}$ CHAPARRO, Verônica Zárate. O Estrangeiro à Luz do Direito Internacional e do Direito Brasileiro: Breves Considerações. In: DEL'OLMO, Florisbal de Souza (Coord). Curso de Direito Internacional Contemporâneo: estudos em homenagem ao professor doutor Luís Ivani Amorim de Araújo pelo seu $80^{\circ}$ aniversário. Rio de Janeiro: Forense, 2003.

${ }^{4}$ Acerca da construção do conceito dessa disciplina, RUSSOMANO. Gilda Maciel Corrêa Meyer. Direito Internacional Privado do Trabalho. Rio de Janeiro: Forense, 1979.

${ }^{5}$ RUSSOMANO. Gilda Maciel Corrêa Meyer. Os Conflitos Espaciais de Leis no Plano das Relações Trabalhistas. José Konfino: Rio de Janeiro, 1964, p. 85.

${ }^{6}$ RUSSOMANO, Os Conflitos, cit., p. 85.

${ }^{7}$ DIPr será utilizado para abreviar Direito Internacional Privado.

${ }^{8}$ DOLINGER, Jacob et al. O DIP no Brasil no século XXI. Revista Mexicana de Derecho Internacional Privado, número especial, p. 79-95, 2000, p. 81.

${ }^{9}$ DOLINGER et al. O DIP, cit., p. 82. Citam-se dois dos principais projetos de lei de introdução ao Código Civil desenvolvidos no Brasil, um deles de autoria de Haroldo Valladão, de 1963, e outro de autoria Jacob Dolinger, de 1995. Nenhum deles, contudo, conseguiu aprovação no Congresso Nacional.
} 
humanos nunca antes observado, conforme se observa do seu art. $4^{\text {o10 }}$. A doutrina realça essa opção como uma orientação internacionalista jamais vista na história constitucional brasileira $^{11}$.

Entretanto, as mudanças promovidas pelas novas diretrizes constitucionais não foram observadas na legislação de DIPr. A última reforma legislativa por que passou a disciplina foi a edição da Lei $\mathrm{n}^{\circ}$ 12.376/10, cuja função foi alterar a denominação da antiga LICC $^{12}$, agora chamada de Lei de Introdução às Normas do Direito Brasileiro ${ }^{13}$. Dessa forma, como não houve alterações substanciais, permanece a crítica à disciplina legislativa da matéria que vinha se fazendo anteriormente ${ }^{14}$.

Nesse contexto, ganha importância o cancelamento da Súmula $n^{\circ} 207$ do Tribunal Superior do Trabalho, em abril de 2012. Editada na década de 1980, determinava que “ $a$ relação jurídica trabalhista é regida pelas leis vigentes no país da prestação do serviço e não por aquelas do local da contratação" 15 .

A mudança na jurisprudência do $\operatorname{TST}^{16}$ demonstra a evolução Corte na área dos conflitos de lei trabalhistas no espaço. O fenômeno da chamada materialização do $\operatorname{DIPr}^{17}$, ocorrido principalmente na Europa, também demonstra seus efeitos na jurisprudência trabalhista brasileira.

O cancelamento da Súmula $\mathrm{n}^{\circ} 207$ originou-se no julgamento de caso envolvendo um trabalhador contratado em 1982 pela Braspetro Oil Service Company (Brasoil), subsidiária da Braspetro Petrobras Internacional S.A., para trabalhar como Guindasteiro em plataforma

\footnotetext{
10 “Art. $4^{\circ}$. A República Federativa do Brasil rege-se nas suas relações internacionais pelos seguintes princípios: I - independência nacional; II - prevalência dos direitos humanos; III - autodeterminação dos povos; IV - nãointervenção; V - igualdade entre os Estados; VI - defesa da paz; VII - solução pacífica dos conflitos; VIII repúdio ao terrorismo e ao racismo; IX - cooperação entre os povos para o progresso da humanidade; X concessão de asilo político. Parágrafo único. A República Federativa do Brasil buscará a integração econômica, política, social e cultural dos povos da América Latina, visando à formação de uma comunidade latinoamericana de nações.”

${ }^{11}$ PIOVESAN, Flávia. Direitos Humanos e Direito Constitucional Internacional. 5 ed., São Paulo: Max Limonad, 2002, p. 62.

${ }^{12}$ LICC serve para abreviar Lei de Introdução ao Código Civil.

${ }^{13}$ FRANCO FILHO, Georgenor de Souza Franco. Contratos Internacionais do Trabalho. Revista Síntese Trabalhista e Previdenciária, v. 23, n. 265, p. 30-43, jul. 2011, p. 31.

${ }_{14}$ JUNIOR, Augusto Jaeger. Europeização do Direito Internacional Privado - Caráter Universal da Lei Aplicável e outros Contrastes com o Ordenamento Jurídico Brasileiro. Curitiba: Juruá, 2012, p. 24.

${ }^{15}$ Acerca das condições do nascimento da Súmula no 207 do TST, ROCHA. Osíris. Contrato Internacional de Trabalho: conseqüências brasileiras. Revista LTr: Legislação do Trabalho, São Paulo, v. 58, n. 05, p. 530-33, maio 1994, p. 531.

${ }^{16}$ TST será usado para abreviar Tribunal Superior do Trabalho.

17 Vale destacar o termo fundamentalização, utilizada por Diego Fernández Arroyo quando se refere às mudanças por que tem passado o DIPr, a fim de se tornar um instrumento para a realização dos direitos fundamentais. Nesse sentido, FERNÁNDEZ ARROYO, Diego Fernández. Prefácio. In: JUNIOR, Augusto Jaeger. Europeização do Direito Internacional Privado - Caráter Universal da Lei Aplicável e outros Contrastes com o Ordenamento Jurídico Brasileiro. Curitiba: Juruá, 2012, p. 10.
} 
petrolífera nas águas na costa de Angola. O contrato foi rescindido em 1998, nos termos da legislação local, e em seguida o empregado ajuizou, com êxito, ação trabalhista em que pedia a aplicação da legislação brasileira, que lhe era mais favorável - a exemplo da prescrição trabalhista brasileira, que é de dois anos, enquanto a angolana é de apenas um ano. Inconformadas com a manutenção da sentença, as empresas recorreram à instância superior buscando a aplicação da legislação territorial, que define o local da prestação de serviço para a resolução do litígio. Nesse julgamento, o Tribunal, após avaliar a evolução do DIPr europeu e se valendo dos elementos de conexão mais atuais dos que os presentes na legislação brasileira, decidiu por afastar o princípio da territorialidade ${ }^{18}$, adotado pela jurisprudência até então vigente no TST.

Dessa forma, o presente artigo busca aferir uma possível evolução do DIPr brasileiro por meio da proteção do empregado, a demonstrar a insuficiência da disciplina clássica. Para isso, num primeiro momento, será analisada a solução dada pelo clássico elemento de conexão da lex laboris ou lex loci executionis, adotado pela Súmula $\mathrm{n}^{\circ}$ 207. E, posteriormente, se verificará a solução de que se valeu o TST para solucionar o caso citado, por meio do elemento de conexão do favor empregado.

\section{A INSUFICIÊNCIA DO MÉTODO CLÁSSICO NA PROTEÇÃO INTERNACIONAL DO EMPREGADO}

O liberalismo jurídico, calcado na lógica racional-formal, originou o sistema do DIPr clássico, como um conjunto de normas geralmente conflituais, indiretas. Essas normas não solucionam a questão jurídica em si, apenas indicam o direito interno aplicável, sendo, assim, classificadas de normas instrumentais ${ }^{19}$ ou normas de colisão ${ }^{20}$, ou, ainda, normas de superdireito $^{21}$. Dessa forma, diante de uma situação que apresente um ou mais elementos de estraneidade $^{22}$, a regra conflitual é autorizada a atuar, conduzindo à descoberta, por meio de um elemento de conexão, da lei aplicável à relação jurídica de caráter internacional.

18 O julgamento do RR-219000-93.2000.5.01.0019, Rel. Ministra Maria Cristina Irigoyen Peduzzi, pela Subseção I Especializada em Dissídios Individuais, em 22 de setembro de 2011, deu origem ao cancelamento da Súmula n 207, por meio da Res. 181 de 23 de abril de 2012 do TST.

${ }^{19}$ DOLINGER, Jacob. Direito internacional privado: parte geral. 7 ed. Rio de Janeiro: Renovar, 2003, p. 51-52.

${ }^{20}$ GOLDSCHMIDT, Werner. Sistema y filosofía del derecho internacional privado. Barcelona: Bosch, 1948, p. 120.

${ }^{21}$ BATALHA, Wilson de Souza Campos. Tratado elementar de direito internacional privado: parte geral. São Paulo: Revista dos Tribunais, 1961, v. 1, p. 85.

${ }^{22}$ Na lição de Elhoueiss (ELHOUEISS, Jean-Luc. L’élément d’extranéité préalable en droit international privé, Journal du Droit International, n. 1, p. 39-85, jan./mars 2003, p. 40), a estraneidade é a qualidade daquilo que é estrangeiro. Contudo, o DIPr não apresenta uma definição precisa de estraneidade. Apenas se destaca que, na 
O sistema clássico foi construído a partir de uma lógica que buscava o que se denomina de "respeito ao conjunto legislativo" ${ }^{23}$. A idéia subjacente às regras aplicáveis a uma situação jurídica está em criar um conjunto coerente, de sorte que uma lei, e apenas uma, deve ser aplicada à situação, sob pena de introduzir um desequilíbrio não desejado entre as partes interessadas na causa. Ao contrário, porém, as regras de conflito, mesmo as mais afinadas, podem traduzir um despedaçamento das situações jurídicas conectadas a mais de sistema jurídico, isto é, as próprias regras de DIPr, eventualmente, criam inúmeras incoerências ${ }^{24}$.

De qualquer forma, no âmbito dessas regras conflituais, podem ser encontrados diversos métodos de indicação da lei aplicável, os quais podem ser classificados a partir de um caráter mais ou menos radical de aceitação do direito advindo dos sistemas jurídicos estrangeiros. Num primeiro estágio, o juiz, destinatário da regra de DIPr, aplica apenas a sua própria lei ou a chamada lex fori ${ }^{25}$. A seguir, enuncia-se o método unilateral. A partir de uma análise da lei do foro, determinam-se as situações internacionais às quais essa lei será aplicada. Dessa forma, por exemplo, ao divórcio de dois estrangeiros, mas domiciliados no país, será aplicada a lei do foro.

Essas regras de conflito prevaleceram até a Primeira Guerra Mundial ${ }^{26}$. Assim, em que pese as soluções do DIPr venha se alterando, a maioria das normas brasileiras é, ainda, pautada nesse método. Nesse sentido, analisam-se a estrutura dessas normas no âmbito da contratação internacional e as soluções para a questão do empregado. Verifica-se, assim, a insuficiência dessa lógica formal para proteger o trabalhador que vem a se sujeitar a um ordenamento jurídico diverso daquele de origem.

\subsection{Normas clássicas}

presença de uma relação de direito privado com ou mais elementos alienígenas, afasta-se a aplicação de regras substanciais de direito interno em benefício das regras de DIPr.

${ }^{23}$ AUDIT, Bernard. Le droit international privé a fin du XXe siècle: progrès ou recul. Revue International de Droit Comparé, n. 2, p. 421-448, avril/juin. 1998, p. 421.

${ }^{24}$ AUDIT, Le droit, cit., p. 421-422.

${ }^{25}$ DROZ, G.A. L. Regards sur le droit international privé comparé. Recueil des Cours de l'Académie de Droit International de La Haye, Hague, v. 4, n. 229, p. 13-423, 1991, p. 29.

${ }^{26}$ OVERBECK, Alfred E. von. Les questions générales du droit international privé à la lumière des codifications récents. Recueil des Cours de l'Academie de Droit International de la Haye, Hague, v. 3, n. 176, p. 13-258, 1983, p. 73. 
Primeiramente se deve fazer uma breve análise acerca do resultado da aplicação dos critérios objetivos do lugar de conclusão do contrato ou do lugar de execução do contrato. Ambos os critérios são considerados elementos de valor geral ${ }^{27}$, na lição de Henri Batiffol ${ }^{28}$.

São dois os argumentos apontados em favor da utilização da lex loci contractus ${ }^{29}$, um de fundo teórico e outro de caráter prático. Por um lado, apresenta-se bastante coerente indicar a lei do local onde as partes dão origem ao contrato como a competente para regê-lo. E por outro, ao favorecer a segurança jurídica, a lex loci contractus também se mostra bastante eficiente: o lugar de nascimento do contrato é apenas um e de fácil determinação. Dessa forma, a lei que está em vigor ou que se aplica ao caso será mais facilmente consultada pelas partes $^{30}$.

Contudo, essas supostas vantagens são fortemente refutadas ${ }^{31}$. Mostra-se difícil qualificar o lugar da conclusão do contrato, quando os contratos são concluídos à distância,

${ }^{27}$ Conforme referem Elsa Dias de Oliveira (OLIVEIRA, Elsa Dias. A proteç̧ão dos consumidores nos contratos celebrados através da internet: contributo para uma análise numa perspectiva material e internacionalprivatista. Coimbra: Almedina, 2002, p. 187) e Fausto Pocar (POCAR, Fausto. La protection de la partie faible em droit international privé. Recueil des Cours de l'Academie de Droit International de la Haye, 1984, Dordrecht/Boston/London, t. 188. p. 339-417, 1986, p. 386), são vários os critérios objetivos que podem determinar a legislação aplicável aos contratos, tais como a língua na qual o contrato está redigido, a escolha do foro ou tribunal arbitral, a aplicação de conceitos jurídicos de uma ordem jurídica determinada, as negociações das partes no período de formação do contrato, a lei escolhida para reger contratos anteriormente celebrados, a nacionalidade ou a residência comum dos contratantes. Já Amílcar de Castro (CASTRO, Amílcar. Direito internacional privado. 5 ed. Rio de Janeiro: Forense, 1997, p. 433-434) elenca outros possíveis critérios, tais como o ius patriae; ou domicilii, do credor, ou do devedor, ou, ainda, o direito conveniente a cada espécie de contrato ou o eleito pelas partes:

${ }^{28}$ BATIFFOL, Henri. Traité élémentaire de droit international privé. 2 ed., Paris: LGDJ, 1955, p. 635.

${ }^{29}$ O critério do local da conclusão dos contratos é adotado na legislação brasileira de DIPr através do art. $9^{\circ}$ da Lei de Introdução: "Para qualificar e reger as obrigações, aplicar-ser-á a lei do país em que se constituírem. $\$ 1^{\circ}$ Destinando-se a obrigação a ser executada no Brasil e dependendo de forma essencial, será esta observada, admitidas as peculiaridades da lei estrangeira quanto aos requisitos extrínsecos do ato. §2 $\mathrm{A}$ obrigação resultante do contrato reputa-se constituída no lugar em que residir o proponente.” (grifo nosso) Contudo, apesar da regra geral brasileira ser a lex loci contractus, a regra relativa à execução tem tido preponderância na jurisprudência pátria (ARAÚJO, Nádia de. Contratos internacionais: autonomia da vontade, Mercosul e convenções internacionais. 3 ed. Rio de Janeiro: Renovar, 2004, p. 123-127), a partir da interpretação de que à lei do local da constituição somam-se as exigências da lei do local de sua execução. E como efetivamente é mais comum ocorrerem litígios em razão do contrato no local de sua execução, por ser este quase sempre o lugar onde o devedor tem seu domicílio, bens e estabelecimentos comerciais, podendo mais facilmente honrar seus compromissos, a lei brasileira, por ser o local da execução, é invariavelmente a lei aplicável.Vale destacar, ainda, o entendimento de Dolinger e Tibúrcio (DOLINGER et al., O DIP, cit., p. 79) sobre a escassez jurisprudencial sobre casos de conflito de leis, a qual é creditada principalmente à mudança do elemento de conexão relativo ao estatuto pessoal, introduzido pela LICC de 1942, que passou da regra da nacionalidade para a regra do domicílio. Assim, o Brasil, país de imigrantes, visando a uma integração plena entre os seus habitantes e a uma maior praticidade, viu diminuir sensivelmente as hipóteses de aplicação de lei estrangeira pelo Judiciário.

${ }^{30}$ BATIFFOL, Traité, cit., p. 636. Vale referir a doutrina de Amílcar de Castro (CASTRO, Direito, cit., p. 444) relacionando a origem do sistema da lex loci contractus ao trabalho dos pós-glosadores.

${ }^{31}$ Em regra, os autores (ARAÚJO, Contratos, cit., p. 121-122; BOGGIANO, Antonio. The contribution of the Hague conference to the development of private international law in Latin America: universality and genus loci. Recueil des Cours de l'Academie de Droit International de la Haye, Hague, n. 233, p. 103-266, 1993, p. 134; OLIVEIRA, A protecção, cit., p. 185) costumam criticar os critérios objetivos de determinação da lei aplicável, ao compará-los à segurança e à previsibilidade proporcionada pelo critério subjetivo, ou seja, pela vontade das partes. 
dependendo-se de se tratar da lex fori ou da lex causae ${ }^{32}$. Também se refere o papel do acaso na contratação internacional como argumento contrário à lex loci contractus. Muitas vezes o lugar de nascimento do contrato apresenta-se fortuito ou acidental para constituir um critério que obedeça aos interesses das partes envolvidas ${ }^{33}$. Nesse sentido, cita-se a experiência jurisprudencial, a qual demonstra que, na grande maioria dos contratos internacionais, o local onde são concluídos os negócios corresponde a grandes centros, nos quais os contratantes não apresentam interesse permanente ${ }^{34}$. Trata-se apenas de locais de encontro, cujos objetivos que levam os contratantes a eles são diferentes daqueles decorrentes dos pactos que lá realizam. Quanto à facilidade de se obter informações acerca da lei aplicável ao contrato, o autor francês não a considera relevante ${ }^{35}$. De fato, na maioria dos casos, os contratantes não costumam questionar a legalidade dos pactos, nem sequer consultam qualquer legislação a respeito. Dessa forma, caso algum conflito venha a se verificar, será muito mais adequado aplicar a legislação que corresponda aos reais interesses das partes. Ademais, caso estiverem realmente interessadas em verificar a legalidade de sua convenção, não se importarão em verificar qualquer lei. Assim, esse argumento acaba se tornando válido apenas para hipóteses muito raras ${ }^{36}$.

Segundo Fausto Pocar, a conexão do lugar da celebração do contrato não favorece a segurança jurídica. Ocorre que são grandes as dificuldades de qualificação ${ }^{37}$ do lugar de conclusão do contrato nos contratos entre ausentes ${ }^{38}$, maioria nos contratos internacionais. Não há homogeneidade entre os sistemas jurídicos de direito material quanto ao local de conclusão entre ausentes: se a qualificação decorrer da lex fori, será o juiz do conflito que a

32 LOUIS-LUCAS, P. La distiction du fond et de la forme dans le règlement des conflits de lois. In: MELANGES Maury, 1960, t. 1, p. 175-205.

33 Amílcar de Castro (CASTRO, Direito, cit., p. 445) traz o exemplo de um brasileiro de passagem pelos Estados Unidos, onde se depara com um amigo argentino, também a passeio, e nesse encontro fortuito fazem um contrato, que ficará então sendo regulado pelo direito norte-americano.

${ }^{34}$ As referências à jurisprudência são trazidas por Henri Batiffol (BATIFFOL, Traité, cit., p. 637-638).

${ }^{35}$ BATIFFOL, Traité, cit., p. 638.

${ }^{36}$ BATIFFOL, Traité, cit., p. 638.

${ }^{37} \mathrm{Na}$ lição de Elhoueiss (ELHOUEISS, Jean-Luc. Retour sur la qualification lege causae en droit international privé. Journal de Droit International, n. 2, p. 281-313, avr./juin. 2005, p. 285), a qualificação constitui o ponto de partida de todo o raciocínio do DIPr clássico. Para o autor, porém, o conceito de categoria jurídica e de qualificação está longe de ser mecânico no âmbito do direito privado. Assim, embora deva se reconhecer o papel fundamental da qualificação, certamente não constitui um problema devidamente adaptado aos fundamentos formais do DIPr Clássico.

${ }^{38}$ Autores brasileiros tradicionais, tais como Clóvis Beviláqua (BEVILAQUA, Clóvis. Princípios elementares de direito internacional privado. Campinas: RED, 2002, p. 206), já se deparavam com tais problemas, conforme trecho a seguir: "Adotando-se o sistema da expedição, [...] o contrato se supõe firmado no momento em que a aceitação é expedida, o lugar do contrato é justamente aquele de onde a aceitação é expedida. Videtur consumari contractus in loco ubi acceptatio facta est, quia illie utriusque consensus coivit. Se o sistema adotado for o da cognição, como a convenção somente se forma depois que o ofertante politicamente toma conhecimento da aceitação, é no domicílio dele que se encontra o lugar do contrato”. 
determinará, já se decorrer da lex causae, há dificuldade de se determinar a lei que rege o contrato, já que depende justamente da determinação do lugar de conclusão.

Relativamente ao lugar da execução do contrato $^{39}$, observam-se inicialmente suas apontadas virtudes, tais como estar a lex loci executionis materialmente conectada com os interesses das partes. Com efeito, há uma tendência secular no DIPr em localizar as relações jurídicas pelo elemento que manifestam exteriormente ou, também dito, materialmente ${ }^{40}$ : daí a preponderância, por exemplo, do estatuto real, ou forum rei sitae, em relação aos bens, ou do lex loci delicti em relação aos atos ilícitos.

Por outro lado, a caracterização do lugar da execução do contrato como critério geral resta afastada quando se verificam situações nas quais o contrato é executado em vários lugares, ou quando tal lugar se apresenta indeterminado ${ }^{41}$. Disso decorre a construção do conceito do lugar da execução principal (lieu d'exécution principal ${ }^{42}$ ), que, no caso da venda de bens móveis, pode ser o lugar do pagamento do preço, por exemplo. Dessa forma, a previsibilidade e a segurança dessa solução acabam igualmente mitigadas. Assim, excetuando-se as hipóteses nas quais a jurisprudência acaba desenvolvendo corretivos para os critérios rígidos $^{43}$, o contrato será submetido a legislações diversas, cuja harmonização pode apresentar problemas delicados ${ }^{44}$.

\subsection{Lex loci laboris}

\footnotetext{
${ }^{39}$ Na América Latina, em especial nos países do Mercosul, Lauro Souza Júnior (SOUZA JÚNIOR, Lauro da Gama e. Os princípios do Unidroit relativos aos contratos comerciais internacionais e sua aplicação nos países do Mercosul. In: RODAS, João Grandino (Org.) Contratos internacionais. São Paulo: Revista dos Tribunais, 2002, p. 427-464, p. 436-439) destaca que o critério da lei do lugar da execução é adotado na Argentina, nos artigos 1.205 a 1.216 do Código Civil; no Uruguai, cuja previsão encontra-se no art. 2.399 do Código Civil e na Lei 10.084/41; por fim, no art. 297 do Código Civil paraguaio. No mesmo sentido, A insuficiente proteção do consumidor nas Normas de Direito Internacional Privado - Da necessidade de uma Convenção Interamericana (CIDIP) sobre Lei Aplicável a Alguns Contratos Relações de Consumo. In: MARQUES, Cláudia Lima. ARAÚJO, Nádia de (Org.). O Novo Direito Internacional - estudos em homenagem a Erik Jayme. Reio de Janeiro, São Paulo e Recife: Renovar, 2005, p. 171-172. Segundo Pocar (POCAR, La protection, cit., p. 386387), a lei do lugar de execução do contrato é bastante frequente na prática legislativa e jurisprudencial, constituindo-se o critério decisivo para a determinação da lei aplicável.

${ }^{40}$ BATIFFOL, Traité, cit., p. 638.

${ }^{41}$ BATIFFOL, Traité, cit., p. 638.

42 BATIFFOL, Traité, cit., p. 639.

${ }^{43}$ Batiffol cita (BATIFFOL, Traité, cit., p. 638-639) uma decisão da Corte Federal Suíça, datada de 10 de junho de 1952, R. 1953.390, na qual foi estabelecida como lei aplicável ao contrato aquela do local de execução da prestação característica da obrigação, a fim de solucionar a diversidade de leis passíveis de aplicação, em virtude do lex loci executionis. Nesse sentido, destaca-se que o desenvolvimento do princípio da autonomia da vontade na definição da lei aplicável às relações privadas internacionais encontra relação com o desenvolvimento do princípio da proximidade (hoje muito utilizado para determinar a legislação aplicável quando da ausência de definição expressa - art. 9 da CIDIP V, por exemplo).

${ }^{44}$ No mesmo sentido, OLIVEIRA, Protecção, cit., p. 195.
} 
A legislação comparada, a doutrina e a jurisprudência, de forma tradicional, têm consagrado, com pequenas exceções, a lex loci laboris ou lex loci executionis como princípio dominante para a solução dos conflitos de leis trabalhistas no espaço nas fases da execução e da cessação do contrato de trabalho ${ }^{45}$. A autora Gilda Russomano afirma que a solução dos conflitos entre leis aplicáveis ao contrato de trabalho é observada pela aplicação Lex loci executionis, pois o lugar da execução surge como elemento relevante ${ }^{46}$.

No Brasil, o critério da lei do local da execução do contrato, considerando-se a relação de trabalho, encontra-se como a solução dos tribunais trabalhistas brasileiros, a ponto de ter sido editada a Súmula n 207 do TST. Atingiu-se esse critério pela conjugação daqueles constantes nos arts. $9^{\circ}, \S 1^{\circ}$, da Lei de Introdução e 651 da CLT. O primeiro manda aplicar a lei brasileira aos contratos executados no país, e o segundo estabelece a competência da Justiça do Trabalho brasileira a partir do lugar onde a prestação de serviços ocorre, ainda que o empregado tenha sido contratado noutro local ou no estrangeiro ${ }^{47}$.

Ainda, o Código de Bustamante, ratificado pelo Brasil e promulgado pelo Decreto $\mathrm{n}^{\mathrm{o}}$ 18.871/29, apresenta uma regra específica acerca dos contratos de trabalho. Em seu art. 198 estabelece ser territorial a legislação sobre acidentes de trabalho e proteção social do trabalhador $^{48}$. Dessa forma, o referido dispositivo foi sendo igualmente usado no âmbito da Justiça do Trabalho para solucionar os conflitos internacionais envolvendo a proteção do empregado.

Importante lembrar que o Código de Bustamante ${ }^{49}$ somente se aplica aos casos em que haja interesses de nacionais dos Estados Americanos que o ratificaram, não sendo observado se houver interesse de nacionais de um mesmo país. A lógica é que, nessas situações, se aplica a lex loci laboris, entre vários elementos de conexão, porque o Estado de origem não iria permitir que seus nacionais se submetessem a condições de trabalho inferiores ao padrão mínimo por ele determinado ${ }^{50}$. Essa situação, contudo, pode nem sempre ser observada.

Assim, o art. $9^{\circ}$ da atual Lei de Introdução às Normas de Direito não teria revogado o art. 198 do Código de Bustamante, pois a lei geral não revoga a especial ${ }^{51}$. Logo, o atrito entre

\footnotetext{
${ }^{45}$ SÜSSEKIND. Arnaldo. Conflitos de Leis do Trabalho. Rio de Janeiro: Freitas Bastos, 1979, p. 26.

${ }^{46}$ RUSSOMANO, Direito, cit., p. 100.

${ }^{47}$ ROCHA, Contrato, cit., p. 531.

${ }^{48}$ MARTINS, Sérgio Pinto. Origens e Fundamentos do Direito Internacional Privado e Relações com o Direito do Trabalho. Revista do Tribunal Regional do Trabalho da $8^{a}$ Região. Belém, v. 30, no 58, p. 107-127, jan./jun. 1997, p. 114.

49 Relatos sobre a obra desenvolvida pelo jurista cubano Antonio Sánchez y Bustamante em DOLINGER, Direito, p. 80-1.

${ }^{50}$ MARTINS, Origens, cit., p. 114-5.

${ }^{51}$ MARTINS, Origens, cit., p. 115.
} 
os arts. $9^{\circ}$ da Lei de Introdução e 198 do Código de Bustamante é apenas aparente, pois o primeiro está vinculado, ostensivamente, no caso, ao art. 17 da mesma norma, que consagra o princípio da ordem pública e, em nome dele, imobiliza a lei estrangeira que seja invocada pela parte interessada ${ }^{52}$.

A lei do lugar da execução do contrato também constitui elemento de conexão na disciplina dos contratos internacionais de trabalho na Europa. Inicialmente previsto no Convênio ou Convenção de Roma, de 1980, hoje substituído pelo Regulamento Roma I ${ }^{53}$, a lex loci laboris continua vigente, juntamente com outros critérios de conexão.

Entretanto, a solução da Súmula $\mathrm{n}^{\circ} 207$ do TST não resolvia todos os problemas jurídicos existentes por meio da aplicação da lex loci laboris ${ }^{54}$. O TST alterou sua posição por meio da percepção de que a lei do lugar da execução do contrato nem sempre garantia a proteção que a condição de vulnerável do empregado exige.

No caso que gerou a mudança na postura da Corte em análise, a aplicação da lei angolana, que obedece ao elemento de conexão próprio do local da execução do contrato, impediria o empregado de ingressar com a demanda. O prazo prescricional para interposição da demanda trabalhista é de apenas um ano naquele país africano, enquanto no Brasil é de dois, nos termos da Constituição Federal ${ }^{55}$. Ainda, na legislação daquele país, restou comprovado não haver previsão de pagamento de qualquer verba ao término do contrato de emprego por mútuo consentimento, sendo permitido o pagamento de compensação monetária pelo não gozo de férias ${ }^{56}$. Em comparação com o padrão de proteção dado pela legislação nacional sobre verbas rescisórias e férias, esse empregado não estaria protegido ${ }^{57}$.

Dessa forma, embora o papel localizador da norma de conexão decorrente da Súmula $\mathrm{n}^{\circ}$ 207 do TST estaria desempenhado satisfatoriamente, a proteção da parte mais fraca restaria esquecida. Assim, o TST passou a procurar novas soluções.

\footnotetext{
${ }^{52}$ Nesse sentido, SPIES, André Luis. Reflexões Trabalhistas acerca do Direito Internacional Privado. Um Pressuposto Científico para Futura Harmonização Legislativa no MERCOSUL. Revista de Jurisprudência Trabalhista do Rio Grande do Sul, ano XV, n 172, Porto Alegre: HS Editora, p. 111-121, abril/1998, p. 118.

${ }^{53}$ Regulamento (CE) n. ${ }^{\circ}$ 593/2008, de 24 de julho de 2008. Acerca do tema, JAEGER, Europeização, p. 68-70.

${ }^{54}$ MARTINS, Origens, cit., p. 116.

${ }^{55}$ Art. $7^{\circ}$, XXIX, da Constituição Federal.

${ }^{56}$ TST, RR-219000-93.2000.5.01.0019, Rel. Ministra Maria Cristina Irigoyen Peduzzi, I Especializada em Dissídios Individuais, julgado em 22 de setembro de 2011.

${ }^{57}$ A proteção à despedida sem justa causa e às férias são direitos fundamentais dos empregados nos termos do art. $7^{\circ}$, I e XVII, da Constituição Federal.
} 


\section{A SOLUÇÃO POR MEIO DA MATERIALIZAÇÃO DO DIREITO INTERNACIONAL PRIVADO}

Dentro do contexto de mudança do DIPr, a transposição de uma política de defesa do contratante mais fraco para uma dimensão jusprivatista internacional nem sempre encontrou apoio unânime da doutrina, por se acreditar que a função do DIPr deveria manter distinta daquela desempenhada pelo direito material ${ }^{58}$. Referem os doutrinadores do Mercosul que, após a década de 1960, caminhou-se no sentido de repensar o método e a idéia de justiça no $\operatorname{DIPr}^{59}$.

O autor Bernard Audit ${ }^{60}$ refere que uma tendência “de fundo" passou a ser observada no âmbito do DIPr. Concernente ao método clássico, houve um recuo da abstração que caracterizava a regra de conflito. Iniciou-se um movimento de busca por um meio termo ou uma alternativa entre a justiça dos conflitos e a justiça do direito material, entre a certeza e a flexibilidade, numa coexistência entre as regras e a abordagem material ${ }^{61}$. Assim, as normas conflituais passaram a perseguir determinados objetivos materiais. E a proteção do trabalhador parte dessa mesma lógica.

A regra de conflito apresenta-se na atualidade como um instrumento de garantia a certos padrões de proteção nas relações privadas internacionais. A busca é pela satisfação de interesses materiais ou governamentais, além de prover as necessidades do comércio e da própria justiça nas relações internacionais. Frisa Audit ${ }^{62}$, porém, que essa preocupação com a justiça aparece mais claramente na doutrina do que na análise das decisões da Corte de Cassação francesa, por exemplo. Atribui essa atitude ao apego do juiz à lei, mas acredita na mudança dessa realidade nos próximos anos.

No direito brasileiro, há exemplos de manifestação desse fenômeno, tanto na legislação quanto na jurisprudência. Em que pese seja possível identificar exemplo até mesmo na Constituição Federal, no âmbito das relações de trabalho houve uma evolução sensível no

\footnotetext{
${ }^{58}$ OLIVEIRA, A proteç̧ão..., p. 179.

${ }^{59}$ FRESNEDO DE AGUIRRE, Cecilia. Aspectos generales del sector del derecho aplicable. In: FERNÁNDEZ ARROYO, Diego P. (Org.). Derecho internacional privado de los estados del MERCOSUR: Argentina, Brasil, Uruguay e Paraguay Buenos Aires: Zavalia, 2003, p. 257-314, p. 300.

${ }^{60}$ AUDIT, Le droit, cit., p. 422.

${ }^{61}$ AUDIT, Le droit, cit., p. 423.

${ }^{62}$ AUDIT, Le droit, cit., p. 438.
} 
tema. Como a proteção do trabalhador exige um constante esforço interpretativo para a garantia desses direitos ${ }^{63}$, facilita-se essa evolução na jurisprudência.

\subsection{Normas de conexões abertas}

As chamadas cláusulas de exceção, ou também chamadas normas de conexões abertas têm sido usadas como corretivo das normas clássicas. Igualmente indiretas, exigem um caráter material e tópico para sua concretização. Representam a tendência a uma ligação entre o critério rígido e a solução flexível: levam em consideração as particularidades do caso, caracterizando uma novidade nos sistemas continentais ${ }^{64}$.

São duas as espécies de relações que privilegiam esse tipo de norma de caráter corretivo: os contratos com consumidores ${ }^{65}$ e os contratos de trabalho. Ambos são baseados em relações especiais, que exigem a proteção a uma parte contratante considerada. A utilização de conexões abertas permite contornar a dificuldade de se criar norma específica de proteção da parte mais fraca. Da mesma forma como a exceção de ordem pública, as cláusulas corretivas requerem uma concretização. Ao contrário da ordem pública, contudo, elas buscam corrigir a conexão, não o resultado material ${ }^{66}$.

O direito europeu apresenta muitas normas dessa espécie. A título de exemplo, a chamada “conexão mais estreita”, norma presente no Regulamento Roma I, é, por si só, muito amplo e passível de diversas concretizações. Essas características podem dificultar a adaptação às necessidades de certeza e previsibilidade das relações privadas internacionais. Outra regra de conexão de caráter aberto é a da "prestação característica”. Essa solução se impôs em razão da sua simplicidade e de motivos sócio-econômicos. Na economia monetária, uma das prestações contratuais consiste no pagamento de uma determinada quantia em dinheiro, que em nada se distingue de outras prestações monetárias similares cumpridas em outros contratos, ainda que sejam de tipo diferente ${ }^{67}$.

\footnotetext{
${ }^{63}$ A respeito do tema, CAMINO, Carmen. Direito Individual do Trabalho, 4 ed., Porto Alegre: Síntese, 2004.

${ }^{64}$ POCAR, La protection, cit., p. 365-366.

${ }^{65}$ Por todos os autores, MARQUES, Cláudia Lima. La propuesta "Buenos Aires". El más reciente avance en el marco de la CIDIP VII de protección de los consumidores. In: JAFFÉ, Angelina et al. (Coord.). Derecho y democracia III. Caracas: UNIMET, 2011. p. 123-160.

${ }^{66}$ JAYME, Erik, Métodos para la concretización del orden público en el derecho internacional privado. Trad. Eugenio Hernández Bretón. Revista de la Facultad de Ciencias Jurídicas y Políticas, n. 82, Universidad Central de Venezuela, Caracas, p. 217-270, 1991, p. 263.

${ }^{67}$ Novamente destaca-se uma decisão da Corte Federal Suíça, datada de 10 de junho de 1952, R. 1953.390, na qual foi estabelecida como lei aplicável ao contrato aquela do local de execução da prestação característica da obrigação, a fim de solucionar a diversidade de leis passíveis de aplicação, em virtude do lex loci executionis (BATIFFOL, Traité, cit., p. 638-639).
} 
Destaca-se que tais conexões abertas são também denominadas de “cláusulas escapatórias” ou “de exceção" ${ }^{68}$. Funcionam para corrigir eventuais falhas dos resultados práticos. Assim, deve ser salientado o caráter excepcional de tal solução, revelando a existência de conexões muito fracas com o ordenamento jurídico designado pela norma de conflito clássica. Dessa forma, a atuação da cláusula de exceção somente ocorre ao verificarse, em concreto, as circunstâncias da causa, o que implica ao intérprete tomar em consideração todas as particularidades de cada caso ${ }^{69}$.

Com relação ao desenvolvimento das cláusulas de conexão abertas nos países de tradição Common Law, deve-se referir que os tribunais ingleses, a partir do século XIX, e em decorrência do desenvolvimento do comércio internacional, passaram a permitir a utilização do princípio da autonomia da vontade na escolha da lei aplicável. Então, passaram a desenvolver um princípio que ficou conhecido como Proper Law, no sentido de que, na ausência de definição da vontade das partes para indicar a lei aplicável, deveria o juiz presumi-la. Para a doutrina inglesa, as partes contratavam sempre com uma lei em mente, cabendo aos tribunais, diante do caso concreto, descobri-la ${ }^{70}$. Nesse sentido, valem os questionamentos trazidos por Vischer $^{71}$, os quais denotam exatamente o conflito que passou a se colocar no âmbito do DIPr dos contratos. Deve o contrato ser localizado como um todo e, assim, questionar-se qual lei (ou qual Estado) governa esse contrato? Ou se deve questionar apenas qual a lei mais relevante, ou mais apropriada para reger o contrato?

Nesse contexto, ganha importância o elemento de conexão favor empregado. Vale apresentar a contribuição de Haroldo Valladão ${ }^{72}$ quanto à aplicação da lei mais favorável. Refere o autor brasileiro que o princípio da lei mais favorável apresenta-se muito antigo e

\footnotetext{
${ }^{68}$ JAYME, Erik, Identité culturalle et intégration : le droit international privé postmoderne. Cours général de droit international privé. Recueil des Cours de l'Académie de Droit International de la Haye, 1995, t. 251. The Hague/Boston/London : Martinus Nijhoff Publishers, 1996, p. 9-268, p. 44-47.

${ }^{69}$ Nesse sentido, a discussão da doutrina europeia acerca da prevalência das cláusulas abertas sobre as normas imperativas e vice-versa, trazida por Cláudia Lima Marques (MARQUES, A insuficiente, cit., p. 184-185).

${ }^{70}$ ARAÚJO, Contratos, cit., p. 64-65.

${ }^{71}$ VISCHER, Frank Benedict. The antagonism between legal security and the search for justice in the field of contracts. Recueil des Cours de l'Academie de Droit International de la Haye, Hague, v. 142, p. 339-396, 1975, p. 16.

72 VALLADÃO, Haroldo. O princípio da lei mais favorável no direito internacional privado. In: ORGANIZAÇÃO DOS ESTADOS AMERICANOS. Curso de derecho internacional. Washington, 1981, p. 522-560, p. 523. Destaca-se que o autor incluiu tal princípio em sua proposta de lei sobre a matéria, na década de 1960, incluindo-o no “Capítulo III, Disposições de DIPr”. Interessante também destacar que o autor, na página 524, defende ter o princípio origem muito remota, já sendo referido na obra de Hugo Grotius. Nas Américas, refere que Teixeira de Freitas já o mencionava, o que deu origem ao art. 14 Código Civil Argentino: "Las leyes extranjeras no serán aplicables: 1ro.) Cuando su aplicación se oponga al derecho público o criminal de la República, a la religión del Estado, a la tolerancia de cultos, o a la moral y buenas costumbres; 2do.) Cuando su aplicación fuere incompatible con el espíritu de la legislación de este Código; 3ro.) Cuando fueren de mero privilegio; 4to.) Cuando las leyes de este Código, en colisión con las leyes extranjeras, fuesen más favorables a la validez de los actos." (grifo nosso).
} 
restrito no âmbito do DIPr, mas tem tomado vulto e amplitude na atualidade. Constitui um elemento de conexão bastante original, pois parte de uma comparação substancial entre a lei do país onde se levantar a questão, habitualmente a lei do foro; a lei nacional e a lei, ou leis estrangeiras que a impregnaram. E conclui-se pela aplicação da lei que for mais favorável, seja à validade do ato, ou ao interesse do menor ou incapaz, ao interesse do filho, ao do pupilo, ao do alimentado, ao do devedor, ao do herdeiro legítimo, etc. Dessa forma, constitui uma solução amplamente aceita, por exemplo, no Direito Internacional Privado de Família ${ }^{73}$.

O autor italiano Fausto Pocar ${ }^{74}$ chamar a atenção de que, para que haja uma efetiva proteção do sujeito mais fraco da relação contratual, deve-se ter presente que muitas vezes uma regra de conexão apenas não se apresenta como única solução. Deve haver uma aplicação conjunta. Deve-se realizar, ao lado da análise do conjunto do método conflitual disponível, um exame material do conteúdo do direito designado pela norma de conflito. Daí a importância do favor empregado.

Nesse sentido, Alfred Overbeck ${ }^{75}$ refere que as soluções inspiradas em preocupações materiais são de três ordens: as regras de conflito podem ser formuladas de maneira a aplicar a (a) lei mais familiar à pessoa que querem proteger; (b) a lei que determine o resultado almejado, como a manutenção de um contrato, o estabelecimento de uma filiação ou a validade de um testamento, ou, enfim, (c) pode deixar uma maior amplitude para as próprias partes envolvidas determinarem elas mesmas a lei aplicável ${ }^{76}$.

No direito brasileiro, podemos identificar na própria Constituição Federal um exemplo de norma prevendo a utilização dessa técnica. O art. 5º XXXI, da Constituição Federal estabelece que “A sucessão de bens de estrangeiros situados no País será regulada pela lei brasileira em benefício do cônjuge ou dos filhos brasileiros, sempre que não lhes seja mais favorável a lei pessoal do de cujus.” Esse dispositivo, além de estabelecer o direito fundamental dos brasileiros, a fim de regular a sucessão com elementos de estraneidade, traz cláusulas abertas e subsidiárias.

\footnotetext{
${ }^{73}$ VALLADÃO, O princípio, cit., p. 522-526.

${ }^{74}$ POCAR, La protection, cit., p. 360.

75 OVERBECK, Les questions, cit., p. 75.

${ }^{76}$ Ancel e Lequette (ANCEL, Bertrand; LEQUETTE, Yves. Les grands arrêts de la jurisprudence française de droit international prvié. 4 ed. Paris: Dalloz, 2001, p. 195) apresentam uma outra classificação tripartite sobre normas conflituais de caráter material: a) a partir da opção do legislador, a exemplo do art. 311-16, al. 2 do Código Civil Francês ("la légitimation par autorité de justice est régie, au choix du requérant, soit par la loi personnelle de celui-ci, soit par la loi personnelle de l'enfant”); b) a partir da atuação do magistrado perante uma pluralidade de leis, a exemplo do art. $5^{\circ}$ do Regulamento Roma I já referido; c) a partir de uma regra que leva em consideração outras regras, a exemplo do art. 311-17 do Código Civil Francês ("la reconnaissance volontaire de paternité ou de maternité est valable si elle a été faite em conformité, soit de la loi personnelle de son auteur, soit de la loi personnelle de l'enfant"). Assim, os resultados materiais buscados pela regra - a validade e o reconhecimento da paternidade ou maternidade - são obtidas se uma das duas leis os consagrar.
} 
Nesse dispositivo constitucional, aparece o princípio da norma mais favorável que, embora bastante antigo, não teve aplicação marcante na legislação jusprivatista. Os elementos de conexão da Lei de Introdução às Normas de Direito Privado ainda se mostram excessivamente rígidos. Assim, embora a regra seja a aplicação da lei brasileira para regular a sucessão dos bens situados no Brasil, considerando o elemento clássico da Lei de Introdução, o dispositivo abre a possibilidade de aplicação da lei estrangeira, caso seja aquela que mais beneficie os herdeiros.

Conforme, então, já ressaltado, enquanto a regra de conflito tradicional se apresenta indiferentemente ao conteúdo das leis em análise, há numerosas regras de DIPr que têm se afastado desse princípio. E esse distanciamento resulta da estrutura desse novo tipo de regras, nas quais prevalecem as conexões alternativas, subsidiárias ou cumulativas ${ }^{77}$. Nos dois primeiros casos, a regra tende a favorecer um resultado. Constata-se que elas são de natureza mista, compostas de um elemento de conexão e de um elemento substancial. Por isso, também são denominadas regras de “conflito com coloração material”78.

Enfim, as pedras angulares do direito interno passaram a ter uma influência sobre a concepção das regras de DIPr, ampliando ao interior desse ramo uma idéia de proteção que se encontrava no seio do direito material.

Portanto, a regra é diretamente substancial quando visa à proteção de uma categoria de pessoas reputadas em situação de vulnerabilidade. Assim, por exemplo, é o artigo $311-18^{79}$ do Código Civil Francês sobre alimentos, sendo que a lei que rege a obrigação de prestá-los pode ser tanto a da residência do alimentando, como a da residência do devedor, à escolha do primeiro.

\footnotetext{
${ }^{77}$ Vale referir uma classificação das normas de DIPr, elaborada por Werner Gosdschmidt (GOLDSCHMIDT, Sistema, cit., p. 189-192), a partir do ponto de conexão que apresentam. Podem ter conexão não-cumulativa simples, tais como aquelas que aplicam uma lei a um determinado aspecto, tais como a conexão sobre propriedade ou posse, que determina a lei do lugar onde está situado o imóvel, por exemplo (art. $8^{\circ}$ da Lei de Introdução.). A conexão pode ser não-cumulativa condicional, subdividida em subsidiária ou condicional. A não-cumulativa condicional subsidiária, ocorre quando a norma indireta apresenta apenas um ponto de contato, mas refere-se também a um segundo (ou subsequente) caso a conexão não se perfectibilize. Já na conexão não-cumulativa condicional alternativa a norma indireta oferece vários pontos de contato, dentre os quais a eleição vai decorrer da livre vontade das partes (autonomia da vontade) ou em virtude de um fato determinado pela regra geral a favor do direito mais favorável em determinado aspecto (favor legis). Podem, por outro lado, as normas terem conexões cumulativas, quando a una só questão, se aplicam vários lei. Subdividemse em iguais e desiguais. As cumulativas iguais ocorrem quando uma mesma questão é submetida a diferentes leis, de forma independente uma da outra; assim, apenas uma coincidência entre as leis aplicáveis permite chegar a uma solução positiva. (art. 2 da Convenção de Haia sobre Separação e Divórcio). Já as cumulativas desiguais consistem em aplicar a uma questão apenas um direito que, inobstante, está submetido à comparação de um outro direito, que serve de guia. Por exemplo, o autor cita o artigo $2^{\circ}$ da lei de 14 de julho de 1891, na qual um co-herdeiro francês deve herdar no estrangeiro, pelo menos, o que herdaria se o direito francês fosse aplicável.

${ }^{78}$ AUDIT, Le droit, cit., p. 427.

79 "Article 311-18 L'action à fins de subsides est régie, au choix de l'enfant, soit par la loi de sa résidence habituelle, soi par la loi de la résidence habituelle du débiteur."
} 


\subsection{Favor empregado}

No final da década de 1970, Gilda Russomano já recomendava o uso, sempre que possível e quando necessário, do princípio da lei mais favorável ao trabalhador, por corresponder ao espírito do direito do Trabalho ${ }^{80}$. Em termos legislativos, no âmbito da proteção internacional do empregado, mesmo antes da Constituição de 1988, a norma mais favorável ao empregado se fez presente no art. $3^{\circ}$, II, da Lei $n^{0} 7.064 / 82^{81}$. Essa lei, juntamente com o Decreto $n^{0}$ 89.339/84, regula a situação dos trabalhadores contratados no Brasil, ou transferidos por empresas prestadoras de serviços de engenharia. Aos demais empregados prevalecia a regra da Súmula $\mathrm{n}^{\mathrm{o}} 207$ do $\mathrm{TST}^{82}$, ou seja, a lex loci executionis, ou a lei do lugar da execução do contrato de trabalho.

Como a regra estava restrita aos trabalhadores do ramo de engenharia, em 2009, foi editada a Lei $\mathrm{n}^{\circ} 11.962 / 09$, estendendo a todos os empregados contratados no país, ou transferidos para o exterior, a regulamentação da Lei ${ }^{0}$ 7.064/82. Em realidade, positivou-se o que a jurisprudência do TST já vinha estabelecendo até então ${ }^{83}$.

Nesse contexto, possuindo o TST uma base legislativa mais ampla, pôde, enfim, proceder ao cancelamento da Súmula $\mathrm{n}^{\circ} 207$ do TST, por meio da Res. $\mathrm{n}^{\circ} 181$ de 16 de abril de 2012. Na mesma decisão que originou o cancelamento, decidiu alargar as hipóteses de aplicação das regras da Lei $n^{0} 7.064 / 1982$.

Portanto, prevalece no TST o seguinte regramento quanto ao trabalhador transferido para o exterior: (a) aplica-se a regra da lex loci executionis para os casos ocorridos antes do advento da Lei $\mathrm{n}^{\circ}$ 11.962/09, quando o trabalhador foi contratado no Brasil para trabalhar diretamente no exterior, sem pertencer ao segmento empresarial referido no texto primitivo da

\footnotetext{
${ }^{80}$ RUSSOMANO, Direito, cit., p. 109.

81 “Art. $3^{\circ}$. A empresa responsável pelo contrato de trabalho do empregado transferido assegurar-lhe-á, independentemente da observância da legislação do local da execução dos serviços: [...] II - a aplicação da legislação brasileira de proteção ao trabalho, naquilo que não for incompatível com o disposto nesta Lei, quando mais favorável do que a legislação territorial, no conjunto de normas e em relação a cada matéria.”

${ }^{82}$ FRANCO FILHO, Contratos, cit., p. 40-1.

${ }^{83}$ RR - 129933/2004-900-01-00.2, Rel. Min. Alberto Luiz Bresciani de Fontan Pereira, julgado em 20 de maio de 2009, 3. ${ }^{a}$ Turma; ROAR - 55560/1999-000-01-00.0, Rel. Min. Kátia Magalhães Arruda, julgado em 02 de outubro de 2007, Subseção II Especializada em Dissídios Individuais; RR - 376707/1997.1, Rel. Min. Maria Cristina Irigoyen Peduzzi, julgado em 12 de dezembro de 2001, 3. ${ }^{\text {T }}$ Turma.
} 
Lei $n^{0} 7.064 / 82$, nem executar qualquer parte do seu contrato no país; (b) aplica-se a Lei ${ }^{\circ}$ 7.064/82 para os trabalhadores contratados no Brasil e transferidos, ou contratados para trabalhar diretamente no exterior no ramo da engenharia; (c) aplica-se a proteção normativa mínima da ordem jurídica trabalhista brasileira ao trabalhador contratado no país, que aqui tenha laborado para seu empregador, sofrendo subsequente remoção para país estrangeiro. Essa última classe de trabalhadores, terá seu contrato de trabalho igualmente regido pelo critério da norma jurídica mais favorável brasileira ou do país estrangeiro, respeitado o conjunto de normas em relação a cada matéria ${ }^{84}$; (d) após o advento da Lei ${ }^{0}$ 11.962/09, aplica-se a Lei $n^{0}$ 7.064/82, para o trabalhador contratado para laborar diretamente no exterior, independentemente do segmento empresarial a que pertença seu empregador.

Verifica-se, assim, que, tendo o trabalhador contato com a lex fori, esse deve ser o seu patamar mínimo de proteção, independentemente do momento em que contratado e do segmento empresarial a que pertença. Ao mesmo tempo em que se reduziram as hipóteses de aplicação da lex loci executionis, regra conflitual clássica, abrangeu-se a possibilidade de utilização da favor empregado, tendo como critério inicial de comparação a lex fori.

A solução do TST não propõe um simples retorno à legislação nacional, possibilitando a aplicação de outras normas estrangeiras, desde que mais favoráveis ao empregado.

\section{CONSIDERAÇÕES FINAIS}

A crescente internacionalização das relações privadas tem trazido mudanças significativas nas relações de trabalho. Diante das particularidades do contrato de trabalho, com a figura de uma parte intrinsecamente mais vulnerável, as mudanças almejadas pela doutrina do DIPr no âmbito das relações contratuais como um todo têm sido experimentadas no âmbito da jurisprudência trabalhista. Nesse ramo trabalhista, a presença de elementos de conexão abertos e alternativos já vem ocorrendo desde a década de 1980, quando nem mesmo a Constituição de 1988, com sua tendência de proteção dos direitos fundamentais e de abertura para as relações internacionais, havia sido editada.

A evolução da jurisprudência do TST no sentido de uma materialização do DIPr se deu por ser mais familiar ao âmbito desta Justiça Especializada o princípio da norma mais favorável. Independentemente disso, o cancelamento da Súmula $\mathrm{n}^{\circ} 207$ do TST indica a percepção da insuficiência do método conflitual clássico na proteção da parte mais fraca.

\footnotetext{
${ }^{84}$ RR - 134700-43.2003.5.02.0060, Rel. Min. Mauricio Godinho Delgado, julgado em 03 de outubro de 2012, 3 ${ }^{\mathrm{a}}$ Turma.
} 
Entretanto, a regra de conexão da lei do lugar da execução do contrato de trabalho ou lex loci laboris deve desaparecer. Conforme preconiza a Lei $n^{0} 7.064 / 82$, pode servir de instrumento alternativo para fixar a lei mais favorável ao empregado. Da mesma forma, o método conflitual clássico não deve ser abandonado. Suas soluções foram construídas ao longo dos séculos, permitindo uma apurada localização do ordenamento jurídico aplicável quando as situações encontram-se conectadas a mais de um Estado. Além disso, permite a harmonização entre os diferentes ordenamentos.

Por outro lado, o resultado da lei indicada aplicável pela norma clássica não pode suprimir os direitos humanos fundamentais. Nesse contexto, a jurisprudência do TST demonstrou que o DIPr brasileiro já não é apenas de índole lógico-formal, mas capaz de assumir uma coloração material.

\section{REFERÊNCIAS}

ANCEL, Bertrand; LEQUETTE, Yves. Les grands arrêts de la jurisprudence française de droit international prvié. 4. ed. Paris: Dalloz, 2001.

ARAÚJO, Nádia de. Contratos internacionais: autonomia da vontade, Mercosul e convenções internacionais. 3. ed. Rio de Janeiro: Renovar, 2004.

AUDIT, Bernard. Le droit international privé a fin du XXe siècle: progrès ou recul. Revue International de Droit Comparé, n. 2, p. 421-448, avril/juin. 1998.

BATALHA, Wilson de Souza Campos. Tratado elementar de direito internacional privado: parte geral. São Paulo: Revista dos Tribunais, 1961.

BATIFFOL, Henri. Traité élémentaire de droit international privé. 2. ed. Paris: LGDJ, 1955.

BEVILAQUA, Clóvis. Princípios elementares de direito internacional privado. Campinas: RED, 2002.

BOGGIANO, Antonio. The contribution of the Hague conference to the development of private international law in Latin America: universality and genus loci. Recueil des Cours de l’Academie de Droit International de la Haye, Hague, n. 233, p. 103-266, 1993. 
CASTRO, Amílcar. Direito internacional privado. 5. ed. Rio de Janeiro: Forense, 1997.

CAMINO, Carmen. Direito individual do trabalho. 4. ed. Porto Alegre: Síntese, 2004.

CHAPARRO, Verônica Zárate. O Estrangeiro à Luz do Direito Internacional e do Direito Brasileiro: Breves Considerações. In: DEL’OLMO, Florisbal de Souza (Coord). Curso de Direito Internacional Contemporâneo: estudos em homenagem ao professor doutor Luís Ivani Amorim de Araújo pelo seu 80 aniversário. Rio de Janeiro: Forense, 2003.

DOLINGER, Jacob et al. O DIP no Brasil no século XXI. Revista Mexicana de Derecho Internacional Privado, número especial, p. 79-95, 2000.

Direito internacional privado: parte geral. 7. ed. Rio de Janeiro: Renovar, 2003.

DROZ, G.A. L. Regards sur le droit international privé comparé. Recueil des Cours de l'Académie de Droit International de La Haye, Hague, v. 4, n. 229, p. 13-423, 1991.

ELHOUEISS, Jean-Luc. L’élément d’extranéité préalable en droit international privé, Journal du Droit International, n. 1, p. 39-85, jan./mars 2003.

Retour sur la qualification lege causae en droit international privé. Journal de Droit International, n. 2, p. 281-313, avr./juin. 2005.

FERNÁNDEZ ARROYO, Diego P. El derecho internacional privado en el inicio del siglo XXI. In: MARQUES, Cláudia Lima; ARAÚJO, Nádia de (Org.) O novo direito internacional: estudos em homenagem a Erik Jayme. Rio de Janeiro: Renovar, 2005.

Prefácio. In: JUNIOR, Augusto Jaeger. Europeização do Direito Internacional Privado - Caráter Universal da Lei Aplicável e outros Contrastes com o Ordenamento Jurídico Brasileiro. Curitiba: Juruá, 2012.

FRADERA, Véra Maria Jacob de. O direito dos contratos no século XXI: a construção de uma noção metanacional de contrato decorrente da globalização, da integração regional e sob 
influência da doutrina comparatista. In: DINIZ, Maria Helena; LISBOA, Roberto Senise. O direito civil no século XXI. São Paulo: Saraiva, 2003.

FRANCO FILHO, Georgenor de Souza Franco. Contratos Internacionais do Trabalho. Revista Síntese Trabalhista e Previdenciária, v. 23, n. 265, p. 30-43, jul. 2011.

GOLDSCHMIDT, Werner. Sistema y filosofía del derecho internacional privado. Barcelona: Bosch, 1948.

JAEGER JUNIOR, Augusto. Europeização do Direito Internacional Privado - Caráter Universal da Lei Aplicável e outros Contrastes com o Ordenamento Jurídico Brasileiro. Curitiba: Juruá, 2012.

JAYME, Erik. Identité culturalle et intégration : le droit international privé postmoderne. Cours général de droit international privé. Recueil des Cours de l'Académie de Droit International de la Haye, 1995, t. 251. The Hague/Boston/London: Martinus Nijhoff Publishers, 1996, p. 9-268.

Métodos para la concretización del orden público en el derecho internacional privado. Trad. Eugenio Hernández Bretón. Revista de la Facultad de Ciencias Jurídicas y Políticas, n. 82, Universidad Central de Venezuela, Caracas, p. 217-270, 1991.

LOUIS-LUCAS, P. La distiction du fond et de la forme dans le règlement des conflits de lois. In: MELANGES Maury, 1960, t. 1, p. 175-205.

MARQUES, Cláudia Lima. A insuficiente proteção do consumidor nas Normas de Direito Internacional Privado - Da necessidade de uma Convenção Interamericana (CIDIP) sobre Lei Aplicável a Alguns Contratos Relações de Consumo. In: MARQUES, Cláudia Lima. ARAÚJO, Nádia de (Org.). O Novo Direito Internacional - estudos em homenagem a Erik Jayme. Reio de Janeiro, São Paulo e Recife: Renovar, 2005.

La propuesta "Buenos Aires". El más reciente avance en el marco de la CIDIP VII de protección de los consumidores. In: JAFFÉ, Angelina et al. (Coord.). Derecho y democracia III. Caracas: UNIMET, 2011. p. 123-160. 
MARTINS, Sérgio Pinto. Origens e Fundamentos do Direito Internacional Privado e Relações com o Direito do Trabalho. Revista do Tribunal Regional do Trabalho da $8^{a}$ Região. Belém, v. 30, nº 58, p. 107-127, jan./jun. 1997.

OLIVEIRA, Elsa Dias. A protecção dos consumidores nos contratos celebrados através da internet: contributo para uma análise numa perspectiva material e internacionalprivatista. Coimbra: Almedina, 2002.

OVERBECK, Alfred E. von. Les questions générales du droit international privé à la lumière des codifications récents. Recueil des Cours de l'Academie de Droit International de la Haye, Hague, v. 3, n. 176, p. 13-258, 1983.

PIOVESAN, Flávia. Direitos Humanos e Direito Constitucional Internacional. 5 ed., São Paulo: Max Limonad, 2002.

ROCHA. Osíris. Contrato Internacional de Trabalho: conseqüências brasileiras. Revista LTr : Legislação do Trabalho, São Paulo, v. 58, n. 05, p. 530-33, maio 1994.

RUSSOMANO. Gilda Maciel Corrêa Meyer. Direito Internacional Privado do Trabalho. Rio de Janeiro: Forense, 1979.

RUSSOMANO. Gilda Maciel Corrêa Meyer. Os Conflitos Espaciais de Leis no Plano das Relações Trabalhistas. José Konfino: Rio de Janeiro, 1964.

SOUZA JÚNIOR, Lauro da Gama e. Os princípios do Unidroit relativos aos contratos comerciais internacionais e sua aplicação nos países do Mercosul. In: RODAS, João Grandino (Org.) Contratos internacionais. São Paulo: Revista dos Tribunais, 2002, p. 427-464.

SPIES, André Luis. Reflexões Trabalhistas acerca do Direito Internacional Privado. Um Pressuposto Científico para Futura Harmonização Legislativa no MERCOSUL. Revista de Jurisprudência Trabalhista do Rio Grande do Sul, ano XV, $\mathrm{n}^{\circ}$ 172, Porto Alegre: HS Editora, p. 111-121, abril/1998. 
SÜSSEKIND. Arnaldo. Conflitos de Leis do Trabalho. Rio de Janeiro: Freitas Bastos, 1979.

VALLADÃO, Haroldo. O princípio da lei mais favorável no direito internacional privado. In: ORGANIZAÇÃO DOS ESTADOS AMERICANOS. Curso de derecho internacional. Washington, 1981, p. 522-560.

VISCHER, Frank Benedict. The antagonism between legal security and the search for justice in the field of contracts. Recueil des Cours de l'Academie de Droit International de la Haye, Hague, v. 142, p. 339-396, 1975. 